\title{
Endosymbiont diversity and community structure in Porites lutea from Southeast Asia are driven by a suite of environmental variables
}

\author{
Yuen Ting Rachel Tan ${ }^{1,2} \cdot$ Benjamin J. Wainwright ${ }^{1,2} \cdot$ Lutfi Afiq-Rosli $\mathrm{i}^{1,3} \cdot$ Yin Cheong Aden Ip ${ }^{1}$. Jen Nie Lee ${ }^{4}$. \\ Nhung Thi Hong Nguyen ${ }^{1}$. Stephen B. Pointing ${ }^{1,2} \cdot$ Danwei Huang ${ }^{1,3}$
}

Received: 1 December 2019 / Accepted: 11 March 2020 / Published online: 6 April 2020

(C) The Author(s) 2020

\begin{abstract}
Many corals depend upon the highly specialised and intricate relationship they form with Symbiodiniaceae algal symbionts. Porites lutea is a massive reef-building coral found throughout Southeast Asia that hosts these endosymbionts obligately. Yet despite the prevalence and importance of $P$. lutea as one of the most dominant corals here, its associated Symbiodiniaceae communities have not been precisely characterised. In this study, we used high-throughput DNA amplicon sequencing of the nuclear internal transcribed spacer 2 (ITS2) to characterise the diversity, community structure and biogeographic distribution of Symbiodiniaceae in P. lutea throughout Singapore and Peninsular Malaysia. Consistent with previous studies, we found that Cladocopium was the most dominant genus among all samples, and Cladocopium $\mathrm{C} 15$ was the most dominant type (or subclade) with $100 \%$ occurrence in all samples from every study site. Results also revealed numerous Symbiodiniaceae types associated with $P$. lutea that were previously undetected in Southeast Asia. Endosymbiont diversity and community variation are driven by a combination of site-specific mean monthly cloud cover and variance in monthly sea surface temperature. This study contributes baseline data toward understanding differences in Symbiodiniaceae assemblages hosted by $P$. lutea, shedding light on how they might be indicative of particular environmental conditions and coral responses.
\end{abstract}

Keywords Algal-coral symbiosis · Biodiversity · Coral reef · ITS2 Peninsular Malaysia - Scleractinia · Singapore · Zooxanthellae

\section{Introduction}

Southeast Asian marine ecosystems are some of the most biologically diverse on the planet (Burke et al. 2002), with 255 coral species recorded in Singapore and over 400 species known from Peninsular Malaysia (Huang et al. 2009; Affendi and

Electronic supplementary material The online version of this article (https://doi.org/10.1007/s13199-020-00671-2) contains supplementary material, which is available to authorized users.

Benjamin J. Wainwright

ben.wainwright@yale-nus.edu.sg

1 Department of Biological Sciences, National University of Singapore, 16 Science Drive 4, Singapore 117558, Singapore

2 Yale-NUS College, National University of Singapore, 16 College Avenue West, Singapore 138527, Singapore

3 Tropical Marine Science Institute, National University of Singapore, 18 Kent Ridge Road, Singapore 119227, Singapore

4 Faculty of Science and Marine Environment, University of Malaysia Terengganu, 21030 Kuala Nerus, Malaysia
Rosman 2011; Huang et al. 2015). The coral reefs of Singapore and Malaysia yield tangible benefits through tourism, fisheries and research estimated at US\$563 million per year (Chou 2000). They provide critical ecological services, buffering against storm impact and mitigating the risk of flooding by reducing wave energy (Heery et al. 2018). However, these reefs are increasingly subjected to the negative impacts of coastal urbanisation and climate change (Fabricius 2005; HoeghGuldberg et al. 2007; Carpenter et al. 2008; Lough et al. 2018; Toh et al. 2018). Singapore's reefs, in particular, are threatened by decades of land reclamation and coastal development, resulting in high sedimentation rates and reduced light levels (Chou 1992; Dikou and Woesik 2006; Lai et al. 2015; Chow et al. 2019). In Malaysia, reefs are threatened by destructive fishing practices, increasing tourism, as well as sedimentation from logging activities, coastal urbanisation and agricultural runoff (Lau et al. 2019).

The persistence of coral reefs and associated communities depends critically on the mutualistic relationship formed between dinoflagellate endosymbionts and their coral hosts (Arif et al. 2014). These photosynthetic endosymbionts belong to 
the highly diverse family Symbiodiniaceae, more commonly known as zooxanthellae (LaJeunesse et al. 2018). The endosymbionts provide up to $90 \%$ of the nutritional requirements of their coral host through photoautotrophy (Muscatine and Porter 1977; Berkelmans and Oppen 2006), increase their host's ability to calcify, and promote the uptake of inorganic nutrients. In return, corals shelter their endosymbionts from grazers, the environment (Arif et al. 2014), and provide them with inorganic nutrients (Stat and Gates 2011). Consequently, Symbiodiniaceae play a critical role in coral reef ecosystems, and the expulsion of these symbionts during extended periods of stress-induced coral "bleaching" can cause widespread mortality of corals and the degradation of coral reef ecosystems (Baker 2003; Stat and Gates 2011; Hughes et al. 2017, 2018).

Reef-building stony corals (Cnidaria: Anthozoa: Scleractinia) associate with a wide range of Symbiodiniaceae taxa (Berkelmans and Oppen 2006). Nine different genus-level clades are currently recognised, with each clade consisting of a number of subclades or types (LaJeunesse et al. 2004a, 2018; Tanzil et al. 2016). Different endosymbionts are associated with varying tolerances to different environmental conditions (Rouzé et al. 2016). For example, the genera Symbiodinium (formerly clade A) and Breviolum (formerly clade B) are more prevalent in shallow-water corals which typically experience higher irradiance (Chen et al. 2003), while Cladocopium (formerly clade C), though widespread, has been found in corals living at greater depth and light-attenuated environments (Innis et al. 2018). Durusdinium (formerly clade D) has been linked to an increased thermal tolerance among host colonies and is thought to be indicative of marginal reef environments (Chen et al. 2003; Stat and Gates 2011; Rouzé et al. 2016). Particular associations between the coral host and endosymbionts can provide ecological advantages in different environments (Berkelmans and Oppen 2006; Fisher et al. 2011), and thus the specific composition of Symbiodiniaceae types living in a coral colony can impact the capacity of the coral host to thrive in its habitat (Muller-Parker et al., 2015).

The factors driving heterogeneity of endosymbiont associations among coral populations are complex (Innis et al. 2018). Previous studies have shown that Symbiodiniaceae diversity in corals is influenced by a variety of biotic and abiotic environmental factors, including (but not limited to) thermal stress, irradiance, freshwater input, salinity, sedimentation, types of symbionts present in the environment, as well as host identity and physiology (Baker 2003; Finney et al. 2010; Kennedy et al. 2016; Ziegler et al. 2017). These effects are in turn influenced by larger scale processes such as ocean circulation in addition to regional and global climate cycles (Stenseth 2002). Consequently, the spatial and geographic distribution of host corals can structure endosymbiont communities. For example, Cladocopium is dominant throughout tropical locations while Symbiodinium, Breviolum and
Fugacium (formerly clade F) are more prevalent at higher latitudes (Baker 2003), while Breviolum is dominant across the Caribbean but is rare or absent in the Indo-Pacific (Lewis et al. 2018). Similarly, thermal history can strongly influence Symbiodiniaceae clade composition (Chen et al. 2003; Fitt et al. 2009; Fisher et al. 2011; Stat and Gates 2011; Hume et al. 2013; Hauff et al. 2016).

Porites lutea is an ecologically important and widespread coral species that contributes substantially to the formation and maintenance of coral reefs throughout the Indian and Pacific Oceans (Stat and Gates 2011; Tanzil et al. 2013). The composition of Symbiodiniaceae communities hosted by this species is known from Japan, Persian Gulf, Red Sea, northern South China Sea, Gulf of Thailand and the Great Barrier Reef (LaJeunesse et al. 2004a; Hume et al. 2013; Gong et al. 2018; Chankong et al. 2019; Terraneo et al. 2019). However, despite the high levels of biodiversity in Southeast Asian marine ecosystems, only limited work using denaturing gel gradient electrophoresis (DGGE) which is limited in its ability to detect symbiont types of low abundance - has been performed in Singapore (Tanzil et al. 2016), and currently no data exist for corals from Peninsular Malaysia.

In this study, we identified Symbiodiniaceae taxa within Porites lutea collected from Singapore and around Peninsular Malaysia, and sought to verify whether Cladocopium is the dominant genus of endosymbionts as previously identified by Tanzil et al. (2016). We also assembled environmental data from throughout the region (sea surface temperature and mean cloud cover) to establish any correlation with Symbiodiniaceae diversity and community structure.

\section{Methods}

\subsection{Sample collection and DNA extraction}

Between 14 and 21 tissue samples measuring approximately $3 \mathrm{~cm}^{2}$ were collected from visibly healthy Porites lutea colonies at each of 15 reef sites across Singapore, eastern and western Peninsular Malaysia (Fig. 1). As per Wainwright et al. (2019), tissues were placed in individual sealed containers that remained in the shade. All samples were immersed in water to minimise thermal stress and preserved in $100 \%$ molecular-grade ethanol within six hours of collection. DNA was extracted with a QIAGEN DNeasy Blood and Tissue Kit following the manufacturer's recommended protocol.

\subsection{Polymerase chain reaction and MiSeq library preparation}

Polymerase chain reactions (PCRs) were carried out to amplify the nuclear ribosomal internal transcribed spacer 2 (ITS2) region (LaJeunesse 2002; Arif et al. 2014) using the forward 


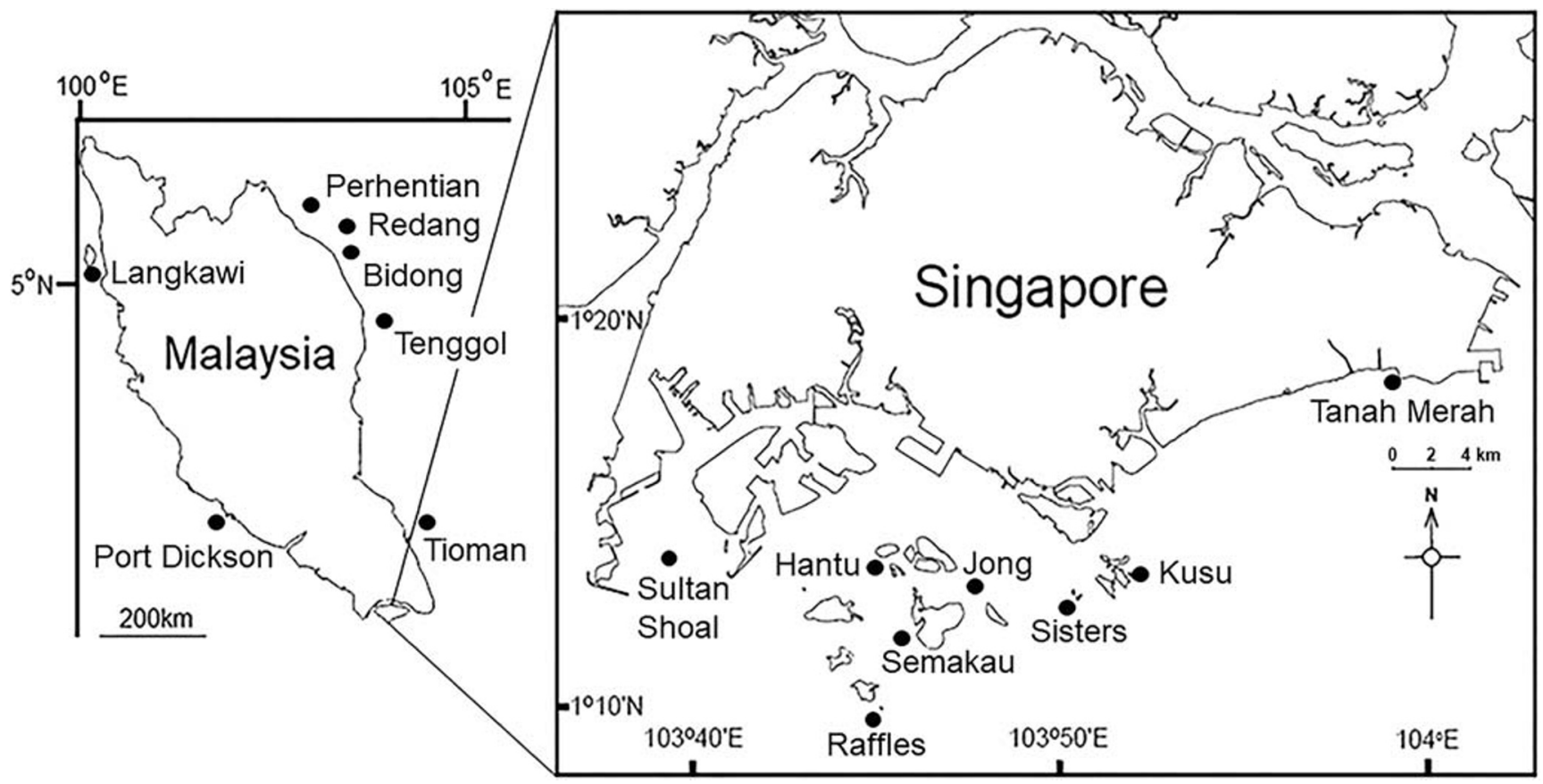

Fig. 1 Sample collection sites throughout Singapore and Peninsular Malaysia

primer ITSintfor2 (5'- GAA TTG CAG AAC TCC GTG - 3') (LaJeunesse and Trench 2000), and reverse primer ITSReverse (5' - GGG ATC CAT ATG CTT AAG TTC AGC GGG T - 3') (Coleman et al. 1994). Unique 8 base-pair (bp) barcodes were generated using Barcode Generator 2.8 (Comai and Howell 2012) and attached to the 5'-end of each primer pair for multiplexed sequencing. PCR was performed in a $25 \mu \mathrm{l}$ reaction volume containing $12.5 \mu \mathrm{l}$ of GoTaq ${ }^{\circledR}$ Green Master Mix (Promega Corporation), $8.5 \mu$ l of water, $1 \mu$ l each of reverse and forward primers at $10 \mu \mathrm{M}$, and $2 \mu \mathrm{l}$ of DNA (diluted 1:10). Thermocycling followed the profile of Lim et al. (2019), with 35 cycles of $30 \mathrm{~s}$ at $94^{\circ} \mathrm{C}, 30 \mathrm{~s}$ at $55^{\circ} \mathrm{C}$, and $45 \mathrm{~s}$ at $72{ }^{\circ} \mathrm{C}$, and a final extension at $72{ }^{\circ} \mathrm{C}$ for $3 \mathrm{~min}$. PCR products were purified with Sera-Mag beads (GE Healthcare). PCR products were normalised and pooled into four separate libraries, with unique 8-bp barcodes in each library. Negative PCR controls without template DNA were included to check for potential contamination. Libraries were sequenced at the Genome Institute of Singapore on the Illumina MiSeq platform using the MiSeq Reagent Kit v2 to generate $2 \times 250 \mathrm{bp}$ reads.

\subsection{Bioinformatics}

Raw data were processed following the pipeline of Sze et al. (2018). Briefly, the Paired-End reAd mergeR (PEAR) program was used to align and merge paired-end reads with overlapping regions of at least 100-bp (Zhang et al. 2013). The following steps were performed in OBITools version 1.2.0 (Boyer et al. 2016): (1) ngsfilter was used to assign reads to individual samples and remove primer sequences; (2) obiannotate was used to label sequences according to sample number and sequence length; (3) obisplit then split each sequence file into a set of subfiles according to their sample numbers; (4) de-replication was carried out using obiuniq, and lastly (5) obigrep was used to filter out sequences represented by single reads as these are indicative of possible amplification or sequencing errors.

Sequences were then searched against the NCBI GenBank database using the Basic Local Alignment Search Tool (BLAST) to positively identify Symbiodiniaceae subclades present in each $P$. lutea sample, based on sequence similarity of $\geq 97 \%$ and E-value $\leq 10^{-5}$. Sequences that were not matched to a GenBank record with type-level identity following the above criteria were discarded.

\subsection{Environmental parameters}

Monthly sea surface temperature (SST) and monthly SST variance in ${ }^{\circ} \mathrm{C}$ were obtained for each site for the months of January 2017 to December 2018 using the NOAA Coral Reef Watch database (https://coralreefwatch.noaa.gov/vs/ data.php), which provides global SST measurements via satellite data at a resolution of $5 \mathrm{~km}$. Monthly cloud cover (\%) was collected for each site using global cloud cover data measured between 2000 and 2014 from Wilson and Jetz (2016), with a resolution of $1 \mathrm{~km}$ (SI Table 1).

\subsection{Statistical analyses}

For each coral sample, endosymbiont type (subclade) richness, Shannon diversity index and proportional abundance 
were characterised. Proportional abundance data were consolidated in a community matrix. The effects of different environmental factors - mean monthly SST, monthly SST variance and mean monthly cloud cover, as well as their interactions - on Shannon diversity were estimated using a generalised linear model (GLM). The Akaike information criterion (AIC) was used for model selection following stepwise simplification of the predictors.

To visualise variation among coral hosts in terms of their endosymbiont community structure, non-metric multidimensional scaling (NMDS) based on Bray-Curtis dissimilarity was performed using the vegan package in $\mathrm{R}$ (Oksanen et al. 2018; R Core Team, 2013). Vectors indicating the effects of mean monthly SST, monthly SST variance and mean monthly cloud cover were fitted onto the ordination. Analysis of Similarities (ANOSIM; 999 permutations) was performed using the Bray-Curtis dissimilarity measure to determine if there were differences in Symbiodiniaceae community structure among regions (i.e. Singapore, eastern and western Peninsular Malaysia).

In addition to the primary dataset which excluded sequences with single reads, a secondary dataset with a more stringent minimum three-read count criterion was assembled to examine the potential effects of false positives, a possible but unlikely consequence of DNA sequencing errors that could be retained in our primary dataset.

\section{Results}

Quality-filtered reads from all four libraries were combined after Illumina MiSeq sequencing, and redundant reads were collapsed (via obiuniq). A total of 42,132,578 assembled paired-end reads were retained, representing a total of 270 samples in the primary dataset (SI Table 2). There were 234 samples in the minimum-three-read secondary dataset. Unless otherwise stated, results and discussions are based on the primary dataset, with any differences highlighted.

A total of 23 distinct Symbiodiniaceae types (subclades) were identified across all samples $(n=270)$ (Table 1). For Singapore samples $(n=153)$, a total of 21 distinct types were identified, with 3 Symbiodinium, 13 Cladocopium and 5 Durusdinium types. For samples from eastern Peninsular Malaysia $(n=84)$, a total of 14 distinct types were identified, with 2 Symbiodinium, 9 Cladocopium and 3 Durusdinium types. For western Peninsular Malaysia samples $(n=33)$, a total of 17 distinct types were identified, with 3 Symbiodinium, 11 Cladocopium and 3 Durusdinium types.

Consistent with previous work in Southeast Asia (LaJeunesse et al. 2010; Leveque et al. 2019; Qin et al. 2019), the top three most common types identified in host colonies from all three regions belonged to the genus Cladocopium (Table 1), though the specific composition differed between regions (Fig. 2 \& SI Fig. 1). Cladocopium $\mathrm{C} 15$ was the most common type identified in all regions and was present in all host colonies sampled (Fig. 2 and SI Fig. 1).

Subclade richness was highest in Singapore, followed by western and then eastern Peninsular Malaysia (Table 1). NMDS and ANOSIM performed on both datasets did not show community structuring or significant differences in endosymbiont diversity between regions (Fig. $3 \&$ SI Fig. 2, ANOSIM minimum-two-read dataset $R=0.042, p=0.098$; ANOSIM minimum-three-read dataset $R=-0.035, p=$ 0.838).

For both datasets, the optimum GLM as determined with AIC was 'Shannon index $\sim$ Monthly SST variance * Mean monthly cloud cover'. For the minimum-two-read dataset all factors were significant, while none were significant at the arbitrarily-defined significance threshold of 0.05 in the more stringent minimum-three-read dataset. However, monthly SST variance and the interaction between monthly SST variance and mean monthly cloud cover were marginally significant ( $p=0.071$ and $p=0.062$ respectively) (Table 2, SI Table 3). The difference between model results was likely due to the reduction in sample size from 270 in the minimum-two-read dataset to 234 in the minimum-threeread dataset, weakening statistical power. Despite this difference, ANOSIM and NMDS were in agreement for both datasets (Fig. 3 \& SI Fig. 2).

\section{Discussion}

In this first study to comprehensively characterise Symbiodiniaceae communities in Porites lutea from Peninsular Malaysia and Singapore, we document numerous endosymbiont types that hitherto have not been detected in Southeast Asia. Cladocopium C15 is the most dominant type and present in all corals from all sampled sites. This dominance pattern in $P$. lutea corals from Singapore is consistent with the findings of Tanzil et al. (2016), which identified subclade $\mathrm{C} 15$ as the only type present in $P$. lutea corals based on DGGE. However, our study demonstrates that a greater diversity of subclades within Symbiodinium, Cladocopium and Durusdinium are hosted by corals from Singapore than previously reported. More broadly in Southeast Asia and in agreement with our work, Cladocopium $\mathrm{C} 15$ has recently been identified as the dominant endosymbiont associated with P. lutea in the Gulf of Thailand (Chankong et al. 2019).

Mean cloud cover, a proxy for irradiance levels, monthly SST variance, and the interaction between these two factors are significant predictors of endosymbiont diversity in $P$. lutea. Model estimates indicate that higher SST variance leads to lower diversity (Table 2), and correspondingly, eastern Peninsular Malaysia has the lowest richness of endosymbionts (Table 1). This pattern is consistent with previous 
Table 1 List of subclades identified in Porites lutea colonies from Singapore, eastern Peninsular Malaysia (PM) and western PM

\begin{tabular}{|c|c|c|c|c|}
\hline \multirow[t]{2}{*}{ Genus } & \multicolumn{4}{|c|}{ List of subclades identified } \\
\hline & All regions & Singapore & eastern PM & western PM \\
\hline \multirow[t]{3}{*}{ Symbiodinium } & A3 & $\checkmark$ & $\checkmark$ & $\checkmark$ \\
\hline & $\mathrm{A} 3 \mathrm{c}$ & $\checkmark$ & - & $\checkmark$ \\
\hline & A6 & $\checkmark$ & $\checkmark$ & $\checkmark$ \\
\hline \multirow[t]{15}{*}{ Cladocopium } & $\mathrm{C} 1$ & $\checkmark * *$ & $\checkmark *$ & $\sqrt{*}$ \\
\hline & C114 & $\checkmark$ & $\checkmark$ & $\checkmark$ \\
\hline & C116 & $\checkmark$ & $\checkmark * *$ & $\sqrt{* *}$ \\
\hline & $\mathrm{C} 15$ & $\sqrt{* * *}$ & $\sqrt{* * *}$ & $\sqrt{* * *}$ \\
\hline & $\mathrm{C} 161$ & $\checkmark$ & $\checkmark$ & $\checkmark$ \\
\hline & $\mathrm{C} 162$ & $\checkmark$ & $\checkmark$ & $\sqrt{* *}$ \\
\hline & $\mathrm{C} 19$ & $\checkmark$ & $\checkmark$ & $\checkmark$ \\
\hline & $\mathrm{C} 21$ & $\checkmark$ & - & - \\
\hline & $\mathrm{C} 3$ & $\checkmark^{*}$ & $\checkmark$ & $\checkmark$ \\
\hline & $\mathrm{C} 35 \mathrm{a}$ & $\checkmark$ & - & - \\
\hline & $\mathrm{C} 4$ & $\checkmark$ & - & - \\
\hline & $\mathrm{C} 60$ & $\checkmark$ & $\checkmark$ & $\checkmark$ \\
\hline & C69a & $\checkmark$ & - & - \\
\hline & $\mathrm{C} 80$ & - & - & $\checkmark$ \\
\hline & C97 & - & - & $\checkmark$ \\
\hline \multirow[t]{5}{*}{ Durusdinium } & D1 & $\checkmark$ & $\checkmark$ & $\checkmark$ \\
\hline & D1a & $\checkmark$ & $\checkmark$ & $\checkmark$ \\
\hline & $\mathrm{D} 1 \mathrm{~b}$ & $\checkmark$ & - & - \\
\hline & D2 & $\checkmark$ & - & - \\
\hline & D5 & $\checkmark$ & $\checkmark$ & $\checkmark$ \\
\hline Total & 23 & 21 & 14 & 17 \\
\hline
\end{tabular}

Asterisks indicate the most commonly found subclades in that region, with $(* * *)$ denoting most common, $(* *)$ denoting second-most common, and (*) denoting third-most common studies showing that SST variance plays a significant role in influencing the diversity of coral endosymbionts (Baker and Romanski 2007; Keshavmurthy et al. 2017). It is conceivable that higher SST variance exerts a selective pressure against endosymbiont types that have lower tolerance for temperature fluctuations or those that are less heat-resistant (Ziegler et al. 2017). Consequently, endosymbiont richness is reduced throughout eastern Peninsular Malaysia where SST variance is highest. Similar ideas have been used to explain the absence of endosymbiont subclades in environments where they may

Fig. 2 Symbiodiniaceae subclade prevalence in Porites lutea colonies based on proportional read abundance from Singapore, eastern and western Peninsular Malaysia (PM). Error bars indicate standard deviation

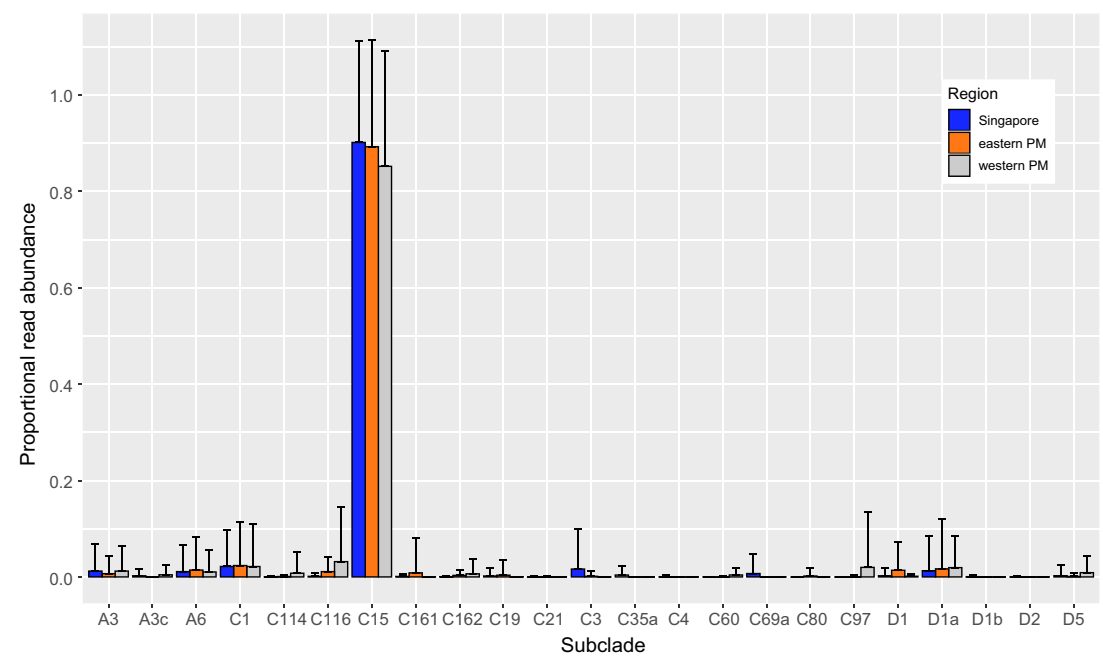




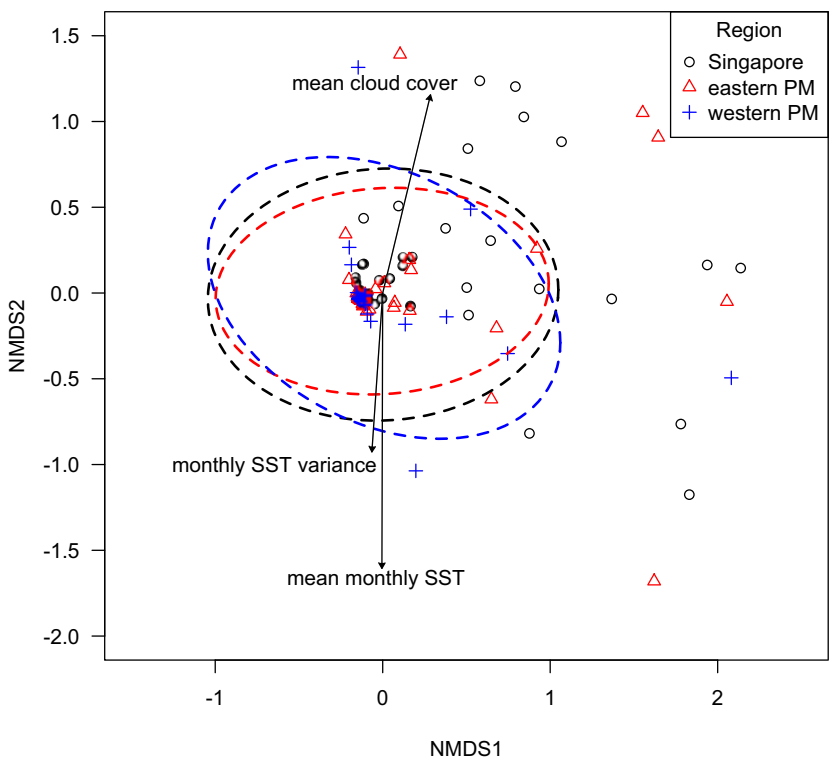

Fig. 3 NMDS based on proportional read count of individual subclades of the primary dataset (minimum read count $=2$ ); each point represents a coral colony sample (stress $=0.0717$ ). Ellipses show how samples from each of the three regions (Singapore, eastern and western PM) are clustered based on a 95\% confidence interval. Length of each vector indicates the amount of influence the environmental factor has in driving variation in subclade communities, with longer vectors indicating greater influence

perform sub-optimally relative to others (Chen et al. 2003; Toller et al. 2001; Stat and Gates 2011).

The influence of mean cloud cover on Symbiodiniaceae diversity is likely due to the effects of irradiance on the photosynthetic abilities of endosymbionts, and consequently the types of endosymbionts taken up by the coral. Studies show that symbiotic associations are, at least to some extent, influenced by the abilities of specific symbionts to exploit different photic environments (Iglesias-Prieto \& Trench, 1994). For example, Cladocopium is more prevalent on shaded sides of Montastraea coral colonies indicating its potential role as a "shade specialist" (Rowan 1998; Savage et al. 2002; Innis et al. 2018). Although the Shannon diversity pattern is not reflective of this effect (Table 2, SI Table 3), our richness data appear to lend support since $P$. lutea found in the extremely turbid and light-attenuated waters of Singapore (Chou 1992;
Dikou and Woesik 2006; Chow et al. 2019) harbours the highest number of Cladocopium types overall (Table 1).

Durusdinium richness is also highest in Singapore. It is well-established that Durusdinium species are tolerant against thermal stress (Chen et al. 2003; Gong et al. 2018; Brian et al. 2019). Studies also suggest that the genus is a possible indicator of marginal reef environments and that its members tend to be more prevalent on reefs with higher levels of environmental disturbance (Chen et al. 2003; Stat and Gates 2011). The close proximity of coral reefs in Singapore to a large urban population and Singapore's role as a major maritime shipping and petrochemical processing hub (Chou 2006; Heery et al. 2018) likely create stresses and disturbances that are not present in other regions (Poquita-Du et al. 2019). On the one hand, subclades D1b and D2 are not associated with P. lutea outside of Singapore possibly because they have been excluded by other endosymbionts better adapted to less stressful environments. In more stressful environments, on the other hand, D1b and D2 may be at a competitive advantage (Chen et al. 2003; Toller et al. 2001), thus accounting for the higher richness of Durusdinium in the more impacted waters of Singapore.

The processes structuring coral symbiont communities can be complex and wide-ranging (Archer et al. 2019), in addition to temperature and cloud cover, Symbiodiniaceae assemblages can be influenced by variables including water chemistry, oceanic processes, sedimentation and pollution (Stat and Gates 2011; Yang et al. 2012; Keshavmurthy et al. 2017; Gong et al. 2018). Seasonally, the varying effects of the northeast monsoon (December to March) and southwest monsoon (June to September) can have different biophysical influences on the three studied regions. The east coast of Peninsular Malaysia has direct exposure to the South China Sea and the northeast monsoon, making it highly susceptible to flooding and freshwater runoff during this period (Varikoden et al. 2011). In comparison, the west coast of Malaysia is reasonably sheltered from southwest monsoonal storms by Sumatra. Furthermore, annual rainfall in eastern Peninsular Malaysia is becoming increasingly variable and torrential (Varikoden et al. 2011; Mayowa et al. 2015). The environmental differences on either side of Peninsular Malaysia are likely responsible, or at least contributing factors that are responsible, for generating the observed disparity in endosymbiont richness between the two regions.
Table 2 Summary of optimal GLM model: Shannon index Monthly SST variance

\begin{tabular}{llll}
\hline & Estimate & Std. Error & $p$-value \\
\hline (intercept) & 55.2193 & 16.4637 & 0.0009 \\
Monthly SST variance & -101.9227 & 29.7158 & 0.0007 \\
Mean monthly cloud cover & -0.7746 & 0.2265 & 0.0007 \\
Monthly SST variance:Mean monthly cloud cover & 1.4021 & 0.4126 & 0.0008 \\
\hline
\end{tabular}

* Mean monthly cloud cover 


\section{Conclusion}

Congruent with other work performed in the Indo-Pacific, our research shows that Cladocopium is the dominant endosymbiont genus hosted by Porites lutea, with $100 \%$ of sampled colonies containing Cladocopium C15 (LaJeunesse et al. 2004b). However, through the use of high-throughput DNA sequencing techniques we show that many more, previously undetected Symbiodiniaceae types are present in P. lutea from Singapore and Peninsular Malaysia.

Considering that Porites lutea is a major reef-building coral in Singapore, Peninsular Malaysia and throughout Southeast Asia, this study contributes important baseline information with which we can begin to understand how corals acclimatise and adapt to changing environmental pressures through adjustments in their endosymbiont communities. Long-term replicated studies conducted at regular intervals on Southeast Asian reefs will provide greater insights into the ways distinct endosymbiont assemblages reflect different environmental conditions. Ultimately, research of this nature allows us to understand, predict, respond to, and manage potential coral bleaching events in this highly biodiverse marine region.

Acknowledgements This study was funded by the National Research Foundation, Prime Minister's Office, Singapore under its Marine Science R\&D Programme (MSRDP-P03 and MSRDP-P38). The funders had no role in study design, data collection and analysis, decision to publish, or preparation of the manuscript.

\section{Compliance with ethical standards}

Ethical approval All applicable permits, international, national, and/or institutional guidelines required to perform the work were followed. Collections from Malaysia were made under permit JTLM 630-7Jld.9(9) and from Singapore under permit numbers NP/RP16-156 and NP/RP18-035.

Conflict of interest The authors declare no conflicts of interests.

Data availability statement The datasets generated during and/or analysed during the current study are available from the corresponding author on reasonable request.

Open Access This article is licensed under a Creative Commons Attribution 4.0 International License, which permits use, sharing, adaptation, distribution and reproduction in any medium or format, as long as you give appropriate credit to the original author(s) and the source, provide a link to the Creative Commons licence, and indicate if changes were made. The images or other third party material in this article are included in the article's Creative Commons licence, unless indicated otherwise in a credit line to the material. If material is not included in the article's Creative Commons licence and your intended use is not permitted by statutory regulation or exceeds the permitted use, you will need to obtain permission directly from the copyright holder. To view a copy of this licence, visit http://creativecommons.org/licenses/by/4.0/.

\section{References}

Affendi YA, Rosman FR (2011) Current knowledge on scleractinian coral diversity of peninsular Malaysia. In: Kamarruddin I, Mohamed CAR, Rozaimi MJ, Kee Alfian AA, Fitra AZ, Lee JN (eds) Malaysia's marine biodiversity: inventory and current status. Department of Marine Park Malaysia, Putrajaya, pp 21-31

Archer SDJ, Lee KC, Caruso T, King-Miaow K, Harvey M, Huang D, Wainwright BJ, Pointing SB (2019) Air mass source determines airborne microbial diversity at the ocean-atmosphere interface of the great barrier reef marine ecosystem. ISME J 14:871-876. https://doi.org/10.1038/s41396-019-0555-0

Arif C, Daniels C, Bayer T et al (2014) Assessing Symbiodinium diversity in scleractinian corals via next-generation sequencing-based genotyping of the ITS2 rDNA region. Molecular Ecology 23: $4418-4433$

Baker A, Romanski A (2007) Multiple symbiotic partnerships are common in scleractinian corals, but not in octocorals: Comment on Goulet (2006). Marine Ecology Progress Series 335:237-242

Baker AC (2003) Flexibility and specificity in coral-algal symbiosis: diversity, ecology, and biogeography of Symbiodinium. Annual Review of Ecology, Evolution, and Systematics 34:661-689

Berkelmans R, Oppen MJV (2006) The role of zooxanthellae in the thermal tolerance of corals: a 'nugget of hope' for coral reefs in an era of climate change. Proceedings of the Royal Society B: Biological Sciences 273:2305-2312

Boyer F, Mercier C, Bonin A et al (2016) Obitools: aunix-inspired software package for DNA metabarcoding. Molecular Ecology Resources 16:176-182

Brian JI, Davy SK, Wilkinson SP (2019) Elevated Symbiodiniaceae richness at Atauro Island (Timor-Leste): a highly biodiverse reef system. Coral Reefs 38:123-136

Burke L, Selig E, Spalding M (2002) Reefs at risk in Southeast Asia. World Resources Institute, Washington, DC, 72 pp

Carpenter KE, Abrar M, Aeby G et al (2008) One-third of reef-building corals face elevated extinction risk from climate change and local impacts. Science 321:560-563

Chankong A, Kongjandtre N, Senanan W, Manthachitra V (2019) Community composition of Symbiodiniaceae among four scleractinian corals in the eastern gulf of Thailand. Reg Stud Mar Sci. https://doi.org/10.1016/j.rsma.2019.100918

Chen A, Lam KK, Nakano Y, Tsai W-S (2003) A stable association of the stress-tolerant zooxanthellae, Symbiodinium Clade D, with the lowtemperature-tolerant coral, Oulastrea crispata (Scleractinia: Faviidae) in subtropical non-reefal coral communities. Zoological Studies 42:4

Chou LM (1992) A guide to the coral reef life of Singapore. Singapore Science Centre

Chou LM (2000) Southeast Asian reefs - status update: Cambodia, Indonesia, Malaysia, Philippines, Singapore, Thailand and Vietnam 2000. Status of Coral Reefs of the World 1-14

Chou LM (2006) Marine habitats in one of the world's busiest harbours. In: Wolanski E (ed) The Environment in Asia Pacific Harbours. Springer, Dordrecht, pp 377-391. https://doi.org/10.1007/1-40203655-8_22

Chow GSE, Chan YKS, Jain SS, Huang D (2019) Light limitation selects for depth generalists in urbanised reef coral communities. Mar Environ Res 147:101-112. https://doi.org/10.1016/j.marenvres. 2019.04.010 
Coleman AW, Suarez A, Goff LJ (1994) Molecular delineation of species and syngens in Volvocacean green algae (Chlorophyta). Journal of Phycology 30:80-90

Comai L, Howell T (2012) Barcode Generator. Retrieved from http:// comailab.genomecenter.ucdavis.edu/index.php/Barcode generator

Dikou A, Woesik RV (2006) Survival under chronic stress from sediment load: Spatial patterns of hard coral communities in the southern islands of Singapore. Marine Pollution Bulletin 52:7-21

Fabricius KE (2005) Effects of terrestrial runoff on the ecology of corals and coral reefs review and synthesis. Marine Pollution Bulletin 50: $125-146$

Finney JC, Pettay DT, Sampayo EM et al (2010) The relative significance of host-habitat, depth, and geography on the ecology, endemism, and speciation of coral endosymbionts in the genus Symbiodinium. Microbial Ecology 60:250-263

Fisher PL, Malme MK, Dove S (2011) The effect of temperature stress on coral-Symbiodinium associations containing distinct symbiont types. Coral Reefs 31:473-485

Fitt W, Gates R, Hoegh-Guldberg O et al (2009) Response of two species of indo-Pacific corals, Porites cylindrica and Stylophora pistillata, to short-term thermal stress: The host does matter in determining the tolerance of corals to bleaching. Journal of Experimental Marine Biology and Ecology 373:102-110

Gong S, Chai G, Xiao Y, Xu L, Yu K, Li J, Liu F, Cheng H, Zhang F, Liao B, Li Z (2018) Flexible symbiotic associations of Symbiodinium with five typical coral species in tropical and subtropical reef regions of the northern South China Sea. Front Microbiol 9. https://doi.org/ 10.3389/fmicb.2018.02485

Hauff B, Haslun JA, Strychar KB et al (2016) Symbiont diversity of zooxanthellae (Symbiodinium spp.) in Porites astreoides and Montastraea cavernosa from a reciprocal transplant in the Lower Florida Keys. International Journal of Biology 8:-9

Heery EC, Hoeksema BW, Browne NK et al (2018) Urban coral reefs: Degradation and resilience of hard coral assemblages in coastal cities of East and Southeast Asia. Marine pollution bulletin 135:654 681

Hoegh-Guldberg O, Mumby PJ, Hooten AJ et al (2007) Coral reefs under rapid climate change and ocean acidification. Science 318:17371742

Huang D, Tun KPP, Chou LM, \& Todd PA (2009) An inventory of zooxanthellae scleractinian corals in Singapore, including 33 new records. Raffles Bulletin of Zoology 1-13

Huang D, Licuanan WY, Hoeksema BW et al (2015) Extraordinary diversity of reef corals in the South China Sea. Marine Biodiversity 45:157-168

Hughes TP, Barnes ML, Bellwood DR, Cinner JE, Cumming GS, Jackson JBC, Kleypas JA, van de Leemput IA, Lough JM, Morrison TH, Palumbi SR, van Nes EH, Scheffer M (2017) Coral reefs in the Anthropocene. Nature 546:82-90. https://doi.org/10. 1038/nature22901

Hughes TP, Kerry JT, Baird AH, Connolly SR, Dietzel A, Eakin CM, Heron SF, Hoey AS, Hoogenboom MO, Liu G, McWilliam MJ, Pears RJ, Pratchett MS, Skirving WJ, Stella JS, Torda G (2018) Global warming transforms coral reef assemblages. Nature 556: 492-496. https://doi.org/10.1038/s41586-018-0041-2

Hume B, D'Angelo C, Burt J et al (2013) Corals from the Persian/Arabian gulf as models for thermotolerant reef-builders: Prevalence of clade C3 Symbiodinium, host fluorescence and ex situ temperature tolerance. Marine Pollution Bulletin 72:313-322

Innis T, Cunning R, Ritson-Williams R et al (2018) Coral color and depth drive symbiosis ecology of Montipora capitata in Kāne'ohe Bay, O‘ahu, Hawai'i. Coral Reefs 37:423-430

Kennedy EV, Tonk L, Foster NL et al (2016) Symbiodinium biogeography tracks environmental patterns rather than host genetics in a key Caribbean reef-builder, Orbicella annularis. Proc R Soc B Biol Sci 283:20161938
Keshavmurthy S, Tang K-H, Hsu C-M, et al (2017) Symbiodinium spp. associated with scleractinian corals from Dongsha Atoll (Pratas), Taiwan, in the South China Sea. PeerJ

Lai S, Loke LH, Hilton MJ et al (2015) The effects of urbanisation on coastal habitats and the potential for ecological engineering: A Singapore case study. Ocean \& Coastal Management 103:78-85

Lau CM, Abdul Adzis K, Affendi YA, Hyde J, Chelliah A, Leong YS, Low YL et al (2019) Tracing coral reefs: a citizen science approach in mapping coral reefs to enhance Marine Park management strategies. Front Mar Sci 6. https://doi.org/10.3389/fmars.2019.00539

LaJeunesse T, Trench R (2000) Biogeography of two species of Symbiodinium (Freudenthal) inhabiting the intertidal sea anemone Anthopleura elegantissima (Brandt). The Biological Bulletin 199: 126-134

LaJeunesse T (2002) Diversity and community structure of symbiotic dinoflagellates from Caribbean coral reefs. Marine Biology 141: $387-400$

LaJeunesse T, Bhagooli R, Hidaka M, DeVantier L, Done T, Schmidt GW, Fitt WK, Hoegh-Guldberg O (2004a) Closely related Symbiodinium spp. differ in relative dominance in coral reef host communities across environmental, latitudinal and biogeographic gradients. Mar Ecol Prog Ser 284:147-161. https://doi.org/10. 3354/meps284147

LaJeunesse T, Thornhill D, Cox E, et al (2004b) High diversity and host specificity observed among symbiotic dinoflagellates in reef coral communities from Hawaii. Coral Reefs 23:596-603

LaJeunesse T, Pettay DT, Sampayo EM et al (2010) Long-standing environmental conditions, geographic isolation and host-symbiont specificity influence the relative ecological dominance and genetic diversification of coral endosymbionts in the genus Symbiodinium. Journal of Biogeography 37:785-800

LaJeunesse T, Parkinson JE, Gabrielson PW, et al (2018) Systematic revision of Symbiodiniaceae highlights the antiquity and diversity of coral endosymbionts. Current Biology 28:2570-2580

Leveque S, Afiq-Rosli L, Ip YCA, Jain SS, Huang D (2019) Searching for phylogenetic patterns of Symbiodiniaceae community structure among indo-Pacific Merulinidae corals. PeerJ 7:e7669. https://doi. org/10.7717/peerj.7669

Lewis AM, Chan AN, LaJeunesse TC (2018) New species of closely related endosymbiotic dinoflagellates in the Greater Caribbean have niches corresponding to host coral phylogeny. Journal of Eukaryotic Microbiology 66:469-482

Lim SSQ, Huang D, Soong K, Neo ML (2019) Diversity of endosymbiotic Symbiodiniaceae in giant clams at Dongsha Atoll, northern South China Sea. Symbiosis 78:251-262

Lough JM, Anderson KD, Hughes TP (2018) Increasing thermal stress for tropical coral reefs: 1871-2017. Sci Rep 6:6079. https://doi.org/ 10.1038/s41598-018-24530-9

Mayowa OO, Pour SH, Shahid S et al (2015) Trends in rainfall and rainfall-related extremes in the east coast of Peninsular Malaysia. Journal of Earth System Science 124:1609-1622

Muscatine L, Porter JW (1977) Reef corals: mutualistic symbioses adapted to nutrient-poor environments. BioScience 27:454-460

Oksanen J, Guillaume FB, Friendly M, et al (2018) Vegan: community ecology package. R package version 2.4-6. https://CRAN.Rproject.org/package $=$ vegan

Poquita-Du RC, Quek ZBR, Jain SS et al (2019) Last species standing: loss of Pocilloporidae corals associated with coastal urbanization in a tropical city state. Mar Biodivers 49:1727-1741. https://doi.org/ 10.1007/s12526-019-00939

Qin Z, Yu K, Chen B, Wang Y, Liang J, Luo W, Xu L, Huang X (2019) Diversity of Symbiodiniaceae in 15 coral species from the southern South China Sea: potential relationship with coral thermal adaptability. Front Microbiol 10:2343. https://doi.org/10.3389/fmicb.2019. 02343 
Rouzé H, Lecellier G, Saulnier D, Berteaux-Lecellier V (2016) Symbiodinium clades a and D differentially predispose Acropora cytherea to disease and Vibrio spp. colonization. Ecology and Evolution 6:560-572

Rowan R (1998) Review-diversity and ecology of zooxanthellae on coral reefs. Journal of Phycology 34:407-417

Savage A, Trapido-Rosenthal H, Douglas A (2002) On the functional significance of molecular variation in Symbiodinium, the symbiotic algae of Cnidaria: photosynthetic response to irradiance. Marine Ecology Progress Series 244:27-37

Stat M, Gates RD (2011) Clade D Symbiodinium scleractinian corals: a "nugget" of hope, a selfish opportunist, an ominous sign, or all of the above? Journal of Marine Biology 2011:1-9

Stenseth NC (2002) Ecological effects of climate fluctuations. Science 297:1292-1296

Sze Y, Miranda LN, Sin TM, Huang D (2018) Characterising planktonic dinoflagellate diversity in Singapore using DNA metabarcoding. Metabarcoding and Metagenomics 2:e25136

Tanzil JT, Brown BE, Dunne RP et al (2013) Regional decline in growth rates of massive Porites corals in Southeast Asia. Global Change biology 19:3011-3023

Tanzil JT, Ng APK, Tey YQ et al (2016) A preliminary characterisation of Symbiodinium diversity in some common corals from Singapore. Cosmos 12:15-27

Terraneo TI, Fusi M, Hume BCC, Arrigoni R, Voolstra CR, Benzoni F, Forsman ZH, Berumen ML (2019) Environmental latitudinal gradients and host-specificity shape Symbiodiniaceae distribution in Red Sea Porites corals. J Biogeogr. https://doi.org/10.1111/jbi.13672

Toh TC, Huang D, Tun K, Chou LM (2018) Summary of coral bleaching from 2014 to 2017 in Singapore. In: Kimura T, Tun K, Chou LM (eds) Status of coral reefs in East Asian Seas region: 2018. Ministry of the Environment of Japan and Japan Wildlife Research Center, Tokyo, pp 21-23

Toller WW, Rowan R, Knowlton N (2001) Zooxanthellae of the Montastraea annularis species complex: patterns of distribution of four taxa of Symbiodinium on different reefs and across depths. Biol Bull 201:348-359

Varikoden H, Preethi B, Samah A, Babu C (2011) Seasonal variation of rainfall characteristics in different intensity classes over Peninsular Malaysia. Journal of Hydrology 404:99-108

Wainwright BJ, Afiq-Rosli L, Zahn GL, Huang D (2019) Characterisation of coral-associated bacterial communities in an urbanised marine environment shows strong divergence over small geographic scales. Coral Reefs 38:1097-1106

Wilson AM, Jetz W (2016) Remotely sensed high-resolution global cloud dynamics for predicting ecosystem and biodiversity distributions. PLOS Biology 14:e1002415

Yang S-Y, Keshavmurthy S, Obura D, et al (2012) Diversity and distribution of Symbiodinium associated with seven common coral species in the Chagos Archipelago, Central Indian Ocean. PLoS ONE

Zhang J, Kobert K, Flouri T, Stamatakis A (2013) PEAR: a fast and accurate Illumina paired-End reAd mergeR. Bioinformatics 30: 614-620

Ziegler M, Arif C, Burt JA et al (2017) Biogeography and molecular diversity of coral symbionts in the genus Symbiodinium around the Arabian Peninsula. Journal of Biogeography 44:674-686

Publisher's note Springer Nature remains neutral with regard to jurisdictional claims in published maps and institutional affiliations. 